\title{
Epigenetic regulations in the IFNy signalling pathway: IFNy- mediated MHC class I upregulation on tumour cells is associated with DNA demethylation of antigen-presenting machinery genes
}

\author{
Veronika VIková ${ }^{1}$, Ivan Štěpánek ${ }^{1}$, Veronika Hruškováa $^{1}$, Filip Šenigl' ${ }^{2}$ Veronika \\ Mayerová ${ }^{1}$, Martin Šrámek ${ }^{1}$, Jana Šímová ${ }^{1}$, Jana Bieblová ${ }^{1}$, Marie Indrová ${ }^{1}$, Tomáš \\ Hejhal $^{1}$, Nicolas Dérian ${ }^{3,4,5,6}$, David Klatzmann ${ }^{3,4,5,6}$, Adrien Six ${ }^{3,4,5,6}$ and Milan Reinišs ${ }^{1}$ \\ ${ }^{1}$ Department of Tumour Immunology, Institute of Molecular Genetics, Academy of Sciences of the Czech Republic, v. v. i., \\ Prague \\ ${ }^{2}$ Department of Viral and Cellular Genetics, Institute of Molecular Genetics, Academy of Sciences of the Czech Republic, v. \\ v. i., Prague \\ ${ }^{3}$ Sorbonne Universités, UPMC Univ Paris 06, UMR 7211, Immunology-Immunopathology-Immunotherapy (I3) Paris, France \\ ${ }^{4}$ CNRS, FRE 3632, Immunology-Immunopathology-Immunotherapy (I3), Paris, France \\ ${ }^{5}$ INSERM, UMR_S 959, Immunology-Immunopathology-Immunotherapy (I3), Paris, France \\ 6 AP-HP, Hôpital Pitié-Salpêtrière, CIC-BTi Biotherapy \& Département Hospitalo-Universitaire (DHU) Inflammation- \\ Immunopathology-Biotherapy (i2B), Paris, France \\ Correspondence to: Milan Reiniš email: reinis@img.cas.cz \\ Keywords: IFNy signalling, DNA demethylation, 5-azacytidine, MHC class I downregulation, tumour immunology \\ Received: July 4, $2014 \quad$ Accepted: July 13, $2014 \quad$ Published: July 15, 2014
}

This is an open-access article distributed under the terms of the Creative Commons Attribution License, which permits unrestricted use, distribution, and reproduction in any medium, provided the original author and source are credited.

\section{ABSTRACT}

Downregulation of MHC class I expression on tumour cells, a common mechanism by which tumour cells can escape from specific immune responses, can be associated with coordinated silencing of antigen-presenting machinery genes. The expression of these genes can be restored by IFNY. In this study we documented association of DNA demethylation of selected antigen-presenting machinery genes located in the MHC genomic locus (TAP-1, TAP-2, LMP-2, LMP-7) upon IFNy treatment with MHC class I upregulation on tumour cells in several MHC class I-deficient murine tumour cell lines (TC-1/A9, TRAMP-C2, MK16 and MC15). Our data also documented higher methylation levels in these genes in TC-1/A9 cells, as compared to their parental MHC class I-positive TC-1 cells. IFNy-mediated DNA demethylation was relatively fast in comparison with demethylation induced by DNA methyltransferase inhibitor 5-azacytidine, and associated with increased histone $\mathrm{H} 3$ acetylation in the promoter regions of APM genes. Comparative transcriptome analysis in distinct MHC class I-deficient cell lines upon their treatment with either IFNy or epigenetic agents revealed that a set of genes, significantly enriched for the antigen presentation pathway, was regulated in the same manner. Our data demonstrate that IFNy acts as an epigenetic modifier when upregulating the expression of antigen-presenting machinery genes.

\section{INTRODUCTION}

Epigenetic changes, such as aberrant DNA methylation, play important roles in carcinogenesis $[1,2]$ and namely in the tumour cell escape from anti-tumour immune responses [3,4]. MHC class I downregulation on tumour cells represents a frequent mechanism by which tumour cells can escape from anti-tumour specific immunity [5-8]. The molecular defects responsible for impaired MHC class I expression on the tumour cell surface can be either irreversible ("hard") or reversible ("soft") [9]. The latter can be associated with coordinated silencing of antigen-presenting machinery (APM) genes in tumour cells $[10,11]$ and the expression of these genes can 
be restored by IFN $\gamma[10,12]$.

An important task is whether epigenetic events, such as changes in DNA methylation, take place in concerted APM gene silencing and IFN $\gamma$-induced restoration of their expression. Evidence that epigenetic mechanisms are important in MHC class I downregulation in APMdeficient tumours and its IFN $\gamma$-mediated induction was brought by Setiadi et al. [13]. The lack of TAP-1 transcription in TAP-deficient cells was associated with low levels of recruitment of histone acetyltransferase CBP (CREB-binding protein) to the TAP-1 promoter. IFN $\gamma$-mediated MHC class I expression corresponded to upregulation of the TAP- 1 expression by increasing histone $\mathrm{H} 3$ acetylation at the TAP-1 promoter locus. Another study documented higher-order chromatin remodelling and subsequent histone hyperacetylation of the human MHC locus upon IFN $\gamma$-mediated activation of the JAK/STAT signalling pathway [14].

We, as well as other laboratories, have previously documented that DNA methylation and histone acetylation might play a role in reversible MHC class I deficiency on the tumour cell surface, since it could be partially restored by the treatment with DNA methyltransferase or histone deacetylase inhibitors [15-17]. This increase was associated with elevated expression of antigen-presenting machinery genes, such as TAP-1, TAP-2, LMP-2 (PSMB9), $L M P-7$ (PSMB8), as well as with DNA demethylation of their corresponding regulatory sequences. We have also shown that chemotherapy of MHC class I-deficient tumours with 5-azacytidine (5AC) in mice increased the expression of the APM genes and associated MHC class I molecule cell surface expression and we have demonstrated 5AC additive effects against MHC class I-deficient tumours when combined with immunotherapy. Notably, the efficacy of this chemoimmunotherapy was partially dependent on the $\mathrm{CD} 8^{+}$-mediated immune responses [18].

Unlike chromatin remodelling and histone acetylation dynamics, the changes in DNA methylation upon activation of the IFN $\gamma$ signalling pathway have not been studied so far. Based on the fact that a set of the APM genes is upregulated by both IFN $\gamma$ and DNA methyltransferase inhibitors, we have hypothesized that IFN $\gamma$-mediated re-activation of silenced APM and some other genes is also associated with their DNA demethylation. The objective of this study was to uncover the association of DNA methylation with IFN $\gamma$-mediated upregulation of genes encoding the components of APM in MHC class I-deficient murine tumour cell lines.

\section{RESULTS}

\section{MHC class I molecule upregulation on tumour cells upon the IFN $\gamma$ treatment}

First, we assessed the level of the MHC class I and APM molecule expression and its modulation by IFN $\gamma$ on the selected tumour cells (Fig. 1a). MHC class I expression on tumour cells after IFN $\gamma$ treatment was upregulated as compared to the tumour cells without treatment. As expected and as has been published previously [19,20], the MHC class I upregulation induced by IFN $\gamma$ was associated with increased expression of APM genes (Fig. 1b). As a negative control, we used the MHC class I-deficient RVP3 cell line that did not respond to the IFN $\gamma$ treatment. TC-1 cells, an MHC class I-positive parental cell line to the TC-1/A9 cells, which also displayed higher APM expression levels, as compared to TC-1/A9 cells, served as an MHC class I-positive control.

\section{The IFN $\gamma$-mediated increase of MHC class I expression on tumour cells and APM gene machinery induction are associated with DNA demethylation of the corresponding APM gene regulatory sequences}

Enhanced APM gene expression in the MHC class I-deficient tumour cells was associated with DNA demethylation of the corresponding gene promoter regions determined by MSP (Fig. 2). We demonstrated DNA demethylation of the promoter sequences of selected antigen-presenting machinery genes (TAP-1/ $L M P-2, T A P-2)$ upon IFN $\gamma$ treatment both in the MHC class I-deficient tumour cell line TC-1/A9 (Fig. 2a) and in the prostate cancer cell line TRAMP-C2 (Fig. 2b). For $L M P-7$, we did not see any dramatic changes in the MSP analysis targeting cytosines located at positions - $186,-190$ and -335 upstream from the LMP-7 transcription start (proximal primers). We therefore analysed CpGs in a more distant region covering CpGs at the positions -1219, -1233 and -1238 and -1087 . In this region, we indeed noticed massive demethylation upon IFN $\gamma$ treatment (distant primers). As a positive control, we used DNA from the MHC class I-positive TC-1 cell line (Fig. 2a), and as a negative control, we used MHC class I-deficient RVP-3 cell line, which did not respond to the IFN $\gamma$ treatment (Fig. 2c). Comparative analysis of the TC- 1 and TC-1/A9 cell lines demonstrated association of the cell surface MHC class I expression levels with DNA demethylation of the APM genes. No demethylation of the APM genes upon IFN $\gamma$ treatment was seen in the RVP-3 cells.

Results from the MSP were confirmed by bisulphite sequencing using the TC-1/A9 cell line (Fig. 3). Again, 
A Control
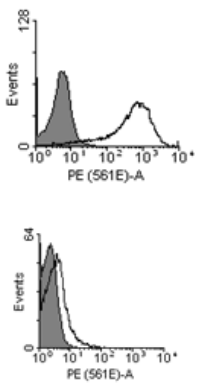

TC-1/A9

TC-1

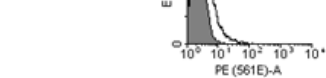

TRAMP-C2

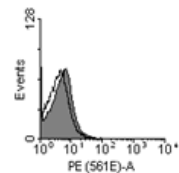

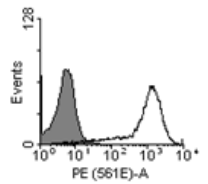
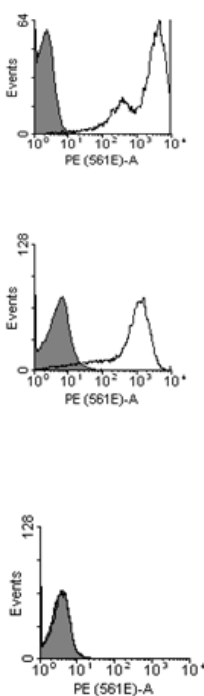

B TAP-1

TAP-2

LMP-2

LMP-7
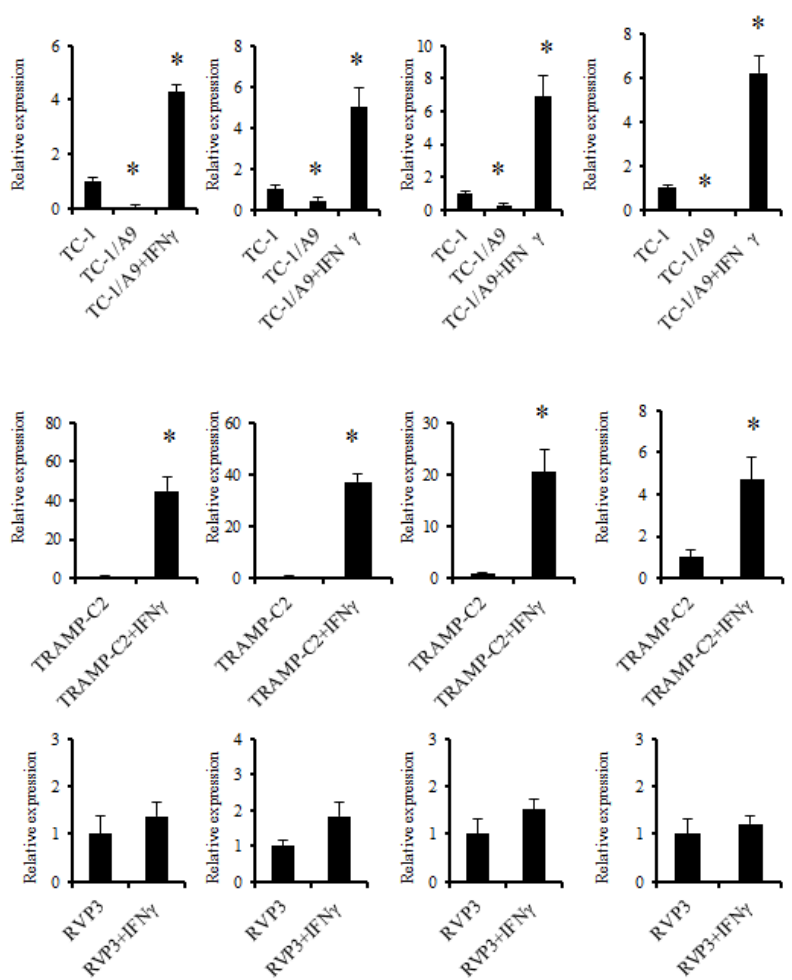

Figure 1: IFN $\gamma$ upregulation of the cell-surface MHC class I expression cells is associated with APM gene expression in experimental tumour cells. MHC class I expression $\left(\mathrm{H}-2 \mathrm{D}^{\mathrm{b}}\right.$ and $\mathrm{H}-2 \mathrm{~K}^{\mathrm{b}}$ together) was determined by the FACS analysis of control tumour cells and after the treatment with IFN $\gamma$. Representative results are presented. (A) Upregulation of APM genes in TC-1/A9 and TRAMP-C2 tumours after treatment with IFN $\gamma$. (B) Expression levels of selected APM genes in TC-1/A9 and TRAMP-C2 control tumour cells and after the treatment with IFN $\gamma$. As a negative control, MHC class I-deficient RVP-3 cell line that did not respond to the IFN $\gamma$ treatment was used. TC-1 cells, a MHC class I-positive parental cell line to the TC-1/A9 cells, that also displayed higher APM expression levels compared to TC-1/A9 cells, served as a MHC class I-positive control. *denote significant changes $(\mathrm{P}<0.05$ determined in Student's $\mathrm{t}$-test) as compared to the values for untreated cells. Biological triplicates were used for the analysis. In all experiments, error bars show standard deviations. Relative expression numbers represent the percentage of the $\beta$-actin expression levels. The levels of relative gene expression were presented as fold changes compared to the levels found in control samples. Experiments were repeated three times with similar results.

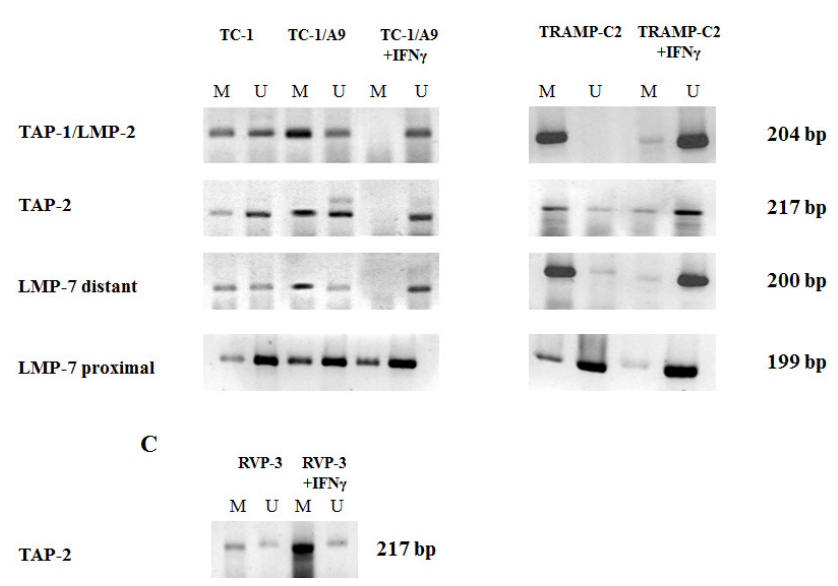

Figure 2: IFN $\gamma$ stimulates DNA demethylation of the APM gene promoter regions. DNA from tumour cell lines cultured in the absence or presence of IFN $\gamma$ were bisulphite treated and subjected to MSP analysis of the TAP-1/LMP-2, TAP-2 and LMP-7 promoter sequences. Higher proportion of DNA methylation, as compared to TC-1 cells and DNA demethylation induced by IFN $\gamma$, is documented in TC-1/A9 cells (A). Similar results were obtained in TRAMP-C2 cells (B), while no effects were noticed in IFN $\gamma$-insensitive RVP-3 tumour cells $(C)$. $U=$ unmethylated primer, $\mathrm{M}=$ methylated. Experiments were repeated three times with similar results. 
strong DNA demethylation of both the TAP-2 and TAP$1 / L M P-2$ gene promoter regions was observed after the treatment with IFN $\gamma$. For LMP-7, we did not see any dramatic changes in a bisulphite sequencing analysis targeting cytosines located at the positions -502 upstream to +130 downstream from the LMP-7 transcription start site. This corresponds with the result from MSP analysis with LMP-7 proximal primers. Based on these results, we can suggest that the methylation status of the distant rather than proximal regulatory sites in the $L M P-7$ region is crucial for their expression.

Both TC-1/A9 and TRAMP-C2 cells represent experimental models for virally transformed tumour cells that do not metastasize. We therefore analysed two more MHC class I-deficient tumour cell lines, metastatic HPV16 E6/E7-positive MK16 and the methylcholantrene-

TAP-2 promoter region

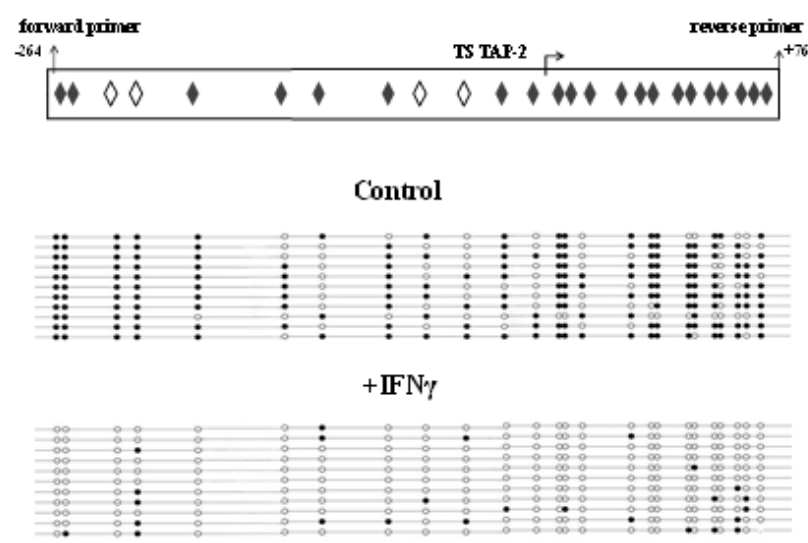

induced MC15 cells (Supplementary Figure 1). Similarly to the experiments with TC-1/A9 and TRAMP-C2 cells, association of the cell surface MHC class I expression levels with DNA demethylation of the APM genes was observed.

\section{DNA demethylation corresponds to the histone $\mathbf{H 3}$ acetylation levels}

ChIP assay was performed to determine whether the dose of IFN $\gamma$ that was sufficient to reverse the methylation of the TAP-1/LMP-2 bidirectional promoter region, as well as $L M P-7$ and $T A P-2$ promoter regions, was able to modify the histones associated with this promoter (Fig. 4). The assay demonstrated that histone $\mathrm{H} 3$ on lysine 18 was re-acetylated after IFN $\gamma$ treatment in all three tested

\section{TAP-1/LMP-2 promoter region}
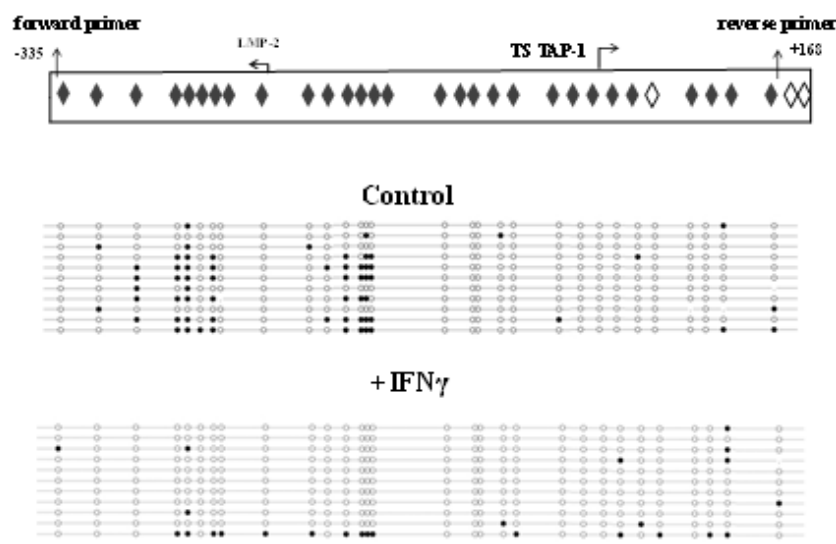

\section{LMP-7 promoter region}
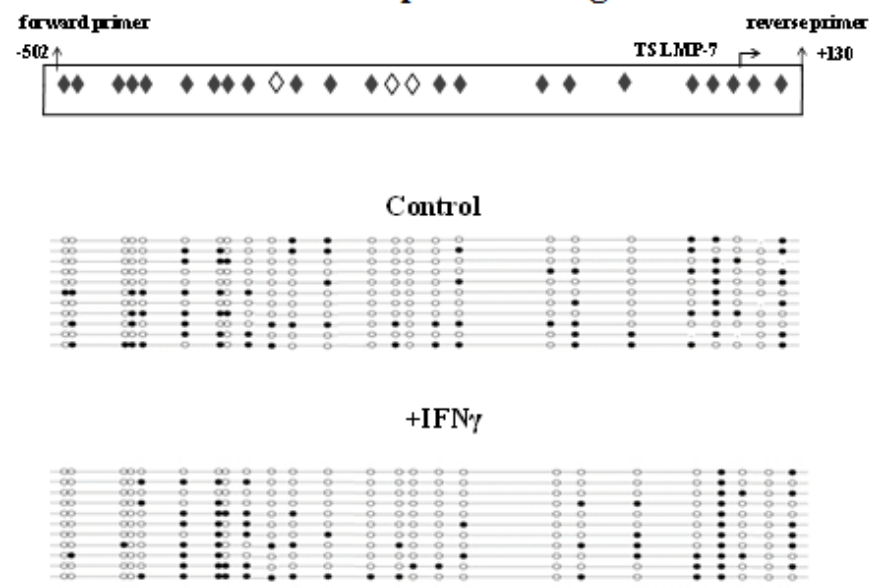

Figure 3: IFN $\gamma$-induced DNA demethylation of the $T A P-2$ and $T A P-1 / L M P-2$ promoters in TC-1/A9 cells analysed by bisulphite sequencing. DNA isolated from treated and control untreated TC-1/A9 cells was subjected to bisulphite conversion and cloned. Sequences from 11 clones from each sample are presented. After treatment with IFN $\gamma$, strong DNA demethylation of both the $T A P-2$ and TAP-1/LMP-2 gene promoter regions was observed. For LMP-7, we did not see any dramatic changes in bisulphite sequencing analysis targeting cytosines located at the positions -502 upstream to +130 downstream from the LMP-7 transcription start site. White and black circles indicate unmethylated and methylated CpGs, respectively. Rhombuses indicate the CpG islands that were investigated with bisulphite sequencing. White colour marks the $\mathrm{CpG}$ islands investigated with MSP. TS: transcription start. 
regions. Acetylated histone $\mathrm{H} 3$ was detected in untreated TC-1/A9 cells at a low level. The TC-1 cell line served as a positive control with high levels of acetylated histone $\mathrm{H} 3$ and, as expected, the acetylation levels were higher in untreated TC-1 cells than in untreated TC-1/A9 cells.

\section{Kinetics of the DNA demethylation}

To examine the kinetics by which the APM promoter regions undergo IFN $\gamma$-mediated changes in DNA methylation, as compared to the effects of a DNA methyltransferase inhibitor, TC-1/A9 cells were treated with either IFN $\gamma$ or $5 \mathrm{AC}$ for various time periods and then by sodium bisulphite conversion and MSP. In untreated cells, the core $\mathrm{CpG}$ island was highly methylated, and demethylation was noticed within $2 \mathrm{~h}$ after IFN $\gamma$ treatment, while nearly maximal demethylation was evident by 6 h (Fig. 5). After 5AC treatment, strong demethylation was evident by $24 \mathrm{~h}$. The kinetics of the $5 \mathrm{AC}$-induced demethylation is in agreement with the fact that $5 \mathrm{AC}$ induced demethylation required DNA replication. On the other hand, the kinetics of the IFN $\gamma$-mediated DNA demethylation suggests that DNA replication was not crucial.

\section{JAK/STAT inhibition studies}

The changes in gene expression by IFN $\gamma$ involve transient increases in the activities of cellular protein tyrosine kinases, including the Janus kinases Jak1 and Jak2, leading to tyrosine phosphorylation of the transcription factor Stat1 [21]. To assess whether the JAK/STAT pathway was crucial for demethylation of the
APM gene promoter regions in TC-1/A9 cells after IFN $\gamma$ treatment, the impacts of an inhibitor of Janus kinases, as well as of STAT1 phosphorylation inhibitor fludarabine on IFN $\gamma$-induced demethylation were investigated (Fig. 6). Both inhibitors blocked IFN $\gamma$-induced STAT1 phosphorylation, although the effect of fludarabine was much weaker, as compared to Janus kinase inhibitor 1 . Indeed, the inhibitor of Janus kinases caused impaired demethylation of the corresponding gene promoter regions, accompanied by decreased relative gene expression of selected APM genes, along with reduction of the MHC class I cell surface expression. Since JAK inhibitor 1 is not solely specific for JAK1, we also used fludarabine, which has been described as a STAT1 phosphorylation specific inhibitor. The effect of fludarabine corresponded to the limited STAT1 phosphorylation inhibition, as observed by the western blot analysis. Both MHC class I cell surface expression and APM gene expression induced by IFN $\gamma$ was only partially inhibited and the MSP results suggested partial DNA demethylation. These results suggest that the classical IFN $\gamma$ signalling pathway takes place in DNA demethylation, although other mechanisms cannot be excluded.

\section{Comparison of the impacts of IFN $\gamma$ and epigenetic agent treatments on the transcriptome of the tumour cell lines}

In these experiments, the aim was to analyse (i) the global impact of IFN $\gamma$ compared to epigenetic treatment (namely DAC/TSA) on the gene expression in the TC-1/ A9 cell line and (ii) whether IFN $\gamma$-induced APM genes can be upregulated upon epigenetic treatment. We compared transcriptome changes upon IFN $\gamma$ vs. DAC/
Chip: TAP-1/LMP-2 promoter

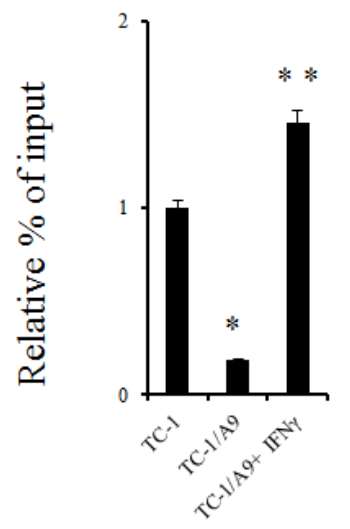

Chip: TAP-2 promoter

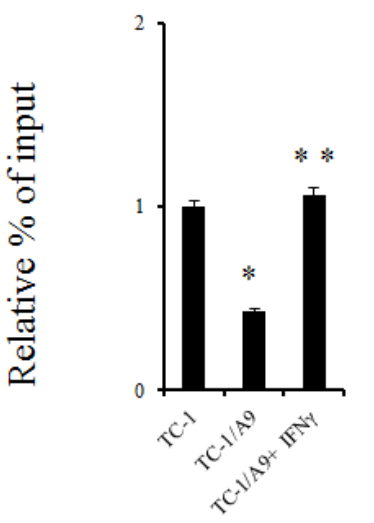

Chip: LMP-7 promoter

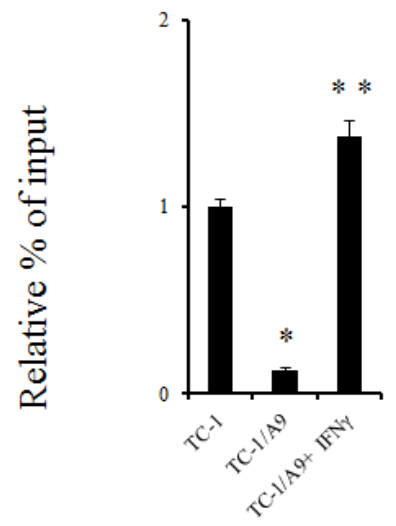

Figure 4: Histone $\mathrm{H3}$ acetylation levels in the APM regulatory gene sequences in TC-1/A9 cells are lower than those in TC-1 cells, but can be increased by IFN $\gamma$. ChIP analysis of chromatin from the TAP-1/LMP-2, TAP-2, and LMP-7 promoter sequences isolated from control and treated TC-1/A9 cells demonstrates an increase in acetylated histone H3 (H3K18) after IFN $\gamma$ treatment. Results were normalized to the levels of the relative input in TC-1 cells. Experiments were repeated five times with similar results. * denotes significant changes $(\mathrm{P}<0.05$ determined in Student's t-test) as compared to the values from TC- 1 cells. ** denotes significant changes $(\mathrm{P}<0.05$ determined in Student's t-test) as compared to the values from TC-1/A9 cells. 
TSA treatments (compared to untreated control cells) of the TC-1/A9 cell line as compared to those of the IFN $\gamma$ non-responding RVP3 cells. IFN $\gamma$-treated TC-1/A9 cells presented 105 significantly upregulated genes $(\mathrm{FDR}<0.01)$ and only two downregulated genes (RIN2 and LBH). Treatment with DAC/TSA provided 2732 significantly upregulated and 2815 downregulated genes. This result can be explained by the fact that IFN $\gamma$ targets specific genes, while DAC acts on the overall genome.

Out of the 105 upregulated genes in IFN $\gamma$-treated TC-1/A9 cells, we defined two gene sets: GS-IFN comprises the 73 genes that were specific to IFN $\gamma$ treatment, when GS-COM comprises the 32 genes that are upregulated upon both treatments (GS-COM and GS-
IFN gene lists are can be seen as Supplementary material, Table 1 and Table 2, respectively). Gene sets were annotated using IPA (Ingenuity®) for pathway enrichment (Benjamini-Hochberg controlled p-values). Both gene sets are significantly enriched for the "Cell Death Of Tumour Cell Lines" pathway ( $p$-value $=1.1 \mathrm{e}-4$ for GS-IFN and $\mathrm{p}$-value $=5.64 \mathrm{e}-3$ for GS-COM): 19 genes are specifically upregulated upon IFN $\gamma$ treatment (CASP4, CASP7, CLEC2D, DDX58, ENC1, FST, GDNF, IL15RA, IL7, IRAK2, IRF1, LGALS3BP, MLKL, SOCS3, STAT2, STAT3, TRIM21, UACA, UBA7). Eight genes are upregulated in both treatments (BID, CREM, EIF $2 A K 2, F A S, H A P 1$, IDO1, STAT1, USP18). As expected, some GS-IFN genes are related to the "Interferon Signaling" pathway (IFIT3,

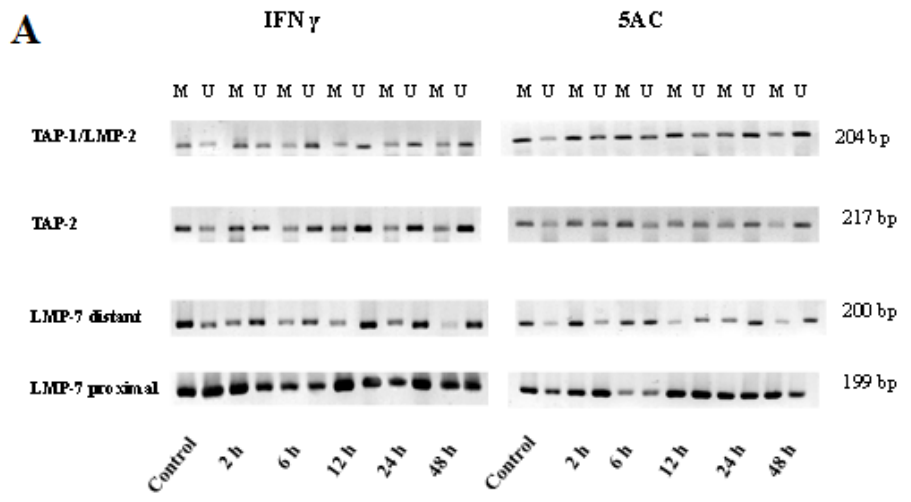

B

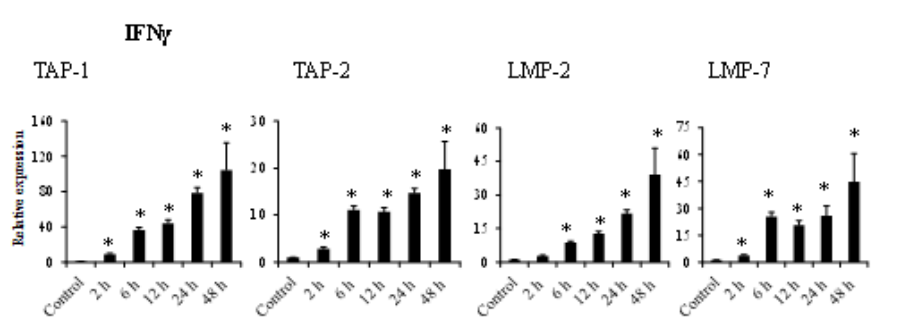

$5 \mathrm{AC}$

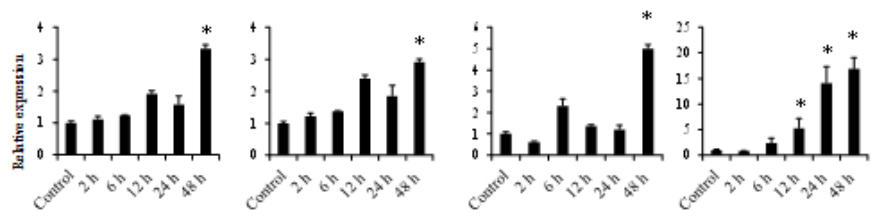

C

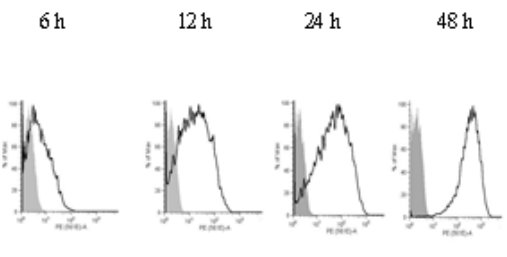

$5 \mathrm{AC}$
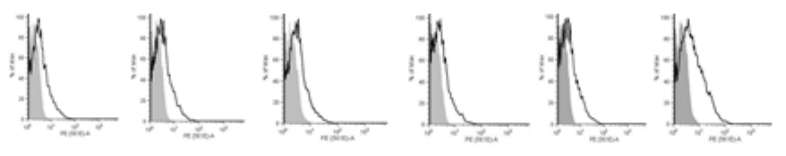

Figure 5: Comparative analysis of the kinetics of DNA demethylation of the APM genes induced by IFN $\gamma$ or 5AC. TC-1/ A9 cells were cultured in the presence of either IFN $\gamma$ or $5 \mathrm{AC}$. For the indicated time periods, DNA samples were isolated, bisulphite treated and subjected to MSP analysis of the TAP-1, TAP-2, LMP-2 \& $L M P-7$ promoter sequences. $\mathrm{U}=$ unmethylated primer, $\mathrm{M}=$ methylated. In untreated cells, the core $\mathrm{CpG}$ island was highly methylated, and demethylation was detected within 2 hours after the IFN $\gamma$ treatment, while nearly complete demethylation was evident by 6 hours (A). After 5AC treatment, strong demethylation was evident by 24 hours (A). The amount of $1 \mu \mathrm{g}$ of RNA was reverse transcribed to cDNA and the PCR products were quantified. Upregulation of APM genes in TC-1/A9 cells after the treatment with IFN $\gamma$ after 2 hours $(\mathrm{A})$ and with $5 \mathrm{AC}$ after 48 hour $(\mathrm{B}) .{ }^{*}$ denote significant changes $(\mathrm{P}<0.05$ determined in Student's t-test) as compared to the values from untreated cells. Biological triplicates were used for the analysis. In all experiments, error bars show standard deviations. Relative expression numbers represent the percentage of the $\beta$-actin expression levels. The levels of relative gene expression were presented as fold changes compared to the levels found in control samples. MHC class I expression $\left(\mathrm{H}-2 \mathrm{D}^{\mathrm{b}}\right.$ and $\mathrm{H}-2 \mathrm{~K}^{\mathrm{b}}$ together) was determined by FACS analysis of the control tumour cells and after the treatment with IFN $\gamma$ and 5AC. Representative results are presented $(\mathrm{C})$. Experiments were repeated three times with similar results. 
IFI35, STAT2, IRF9, TAP1, IRF1; p-value $=2.38 \mathrm{e}-7$ ). Strikingly, GS-COM annotation identifies the "Antigen Presentation" pathway (HLA-G, LMP-2 (PSMB9), HLA-B, LMP-7 (PSMB8), TAP2, TAPBP, HLA-E; p-value $=1.23 \mathrm{e}-$ 11).

Consistent results were obtained when comparing the impact of IFN $\gamma$ on TC-1/A9 cells (IFN $\gamma$ and DAC/ TSA sensitive) and DAC/TSA effects on the RVP3 cell line (IFN $\gamma$ resistant though DAC/TSA sensitive). The 40 upregulated genes in both conditions show enrichment for the "Antigen Presentation" pathway (HLA-B, HLA-E, HLA-G, NLRC5, TAP2, TAPBP; p-value=1.6e-8) and the 65 IFN $\gamma$-specific gene set is also enriched for the "Interferon Signaling" pathway (IFIT3, IRF1, IRF9, LMP-7 (PSMB8), STAT2, TAP1; p-value =1.16e-7).

\section{DISCUSSION}

IFN $\gamma$ is a cytokine with pleiotropic effects on tumour cells, which is also considered as a crucial mediator of effective antitumour immunity displaying direct impacts on tumour cells [22]. The principal aims of our study were to determine whether IFN $\gamma$ acts as an epigenetic modifier inducing DNA demethylation and whether the mechanisms by which IFN $\gamma$ upregulates the expression of selected genes in MHC class I-deficient tumour cells and thus modifies their interactions with the immune system can be associated with DNA demethylation of the corresponding regulatory genes. Reversible MHC class I downregulation on tumour cells can be associated with impaired expression of a number different genes, such as genes encoding MHC class I heavy chains, $\beta 2-$ microglobulin, APM components including LMP-2, LMP7, TAP-1, TAP-2 and tapasin, which can be coordinated and epigenetically regulated $[7,23]$. H-2 $\mathrm{D}^{\mathrm{b}}, \mathrm{H}-2 \mathrm{~K}^{\mathrm{b}}, \beta 2-$ microglobulin and APM (LMP-2 LMP-7, TAP-1, TAP2 and tapasin gene expression in our principal model, TC-1/A9, has been analysed previously $[15,16,19]$. While the expression of genes encoding $\mathrm{H}-2 \mathrm{D}^{\mathrm{b}}, \mathrm{H}-2 \mathrm{~K}^{\mathrm{b}}, \beta 2-$ microglobulin and tapasin remained robust in TC-1/A9,

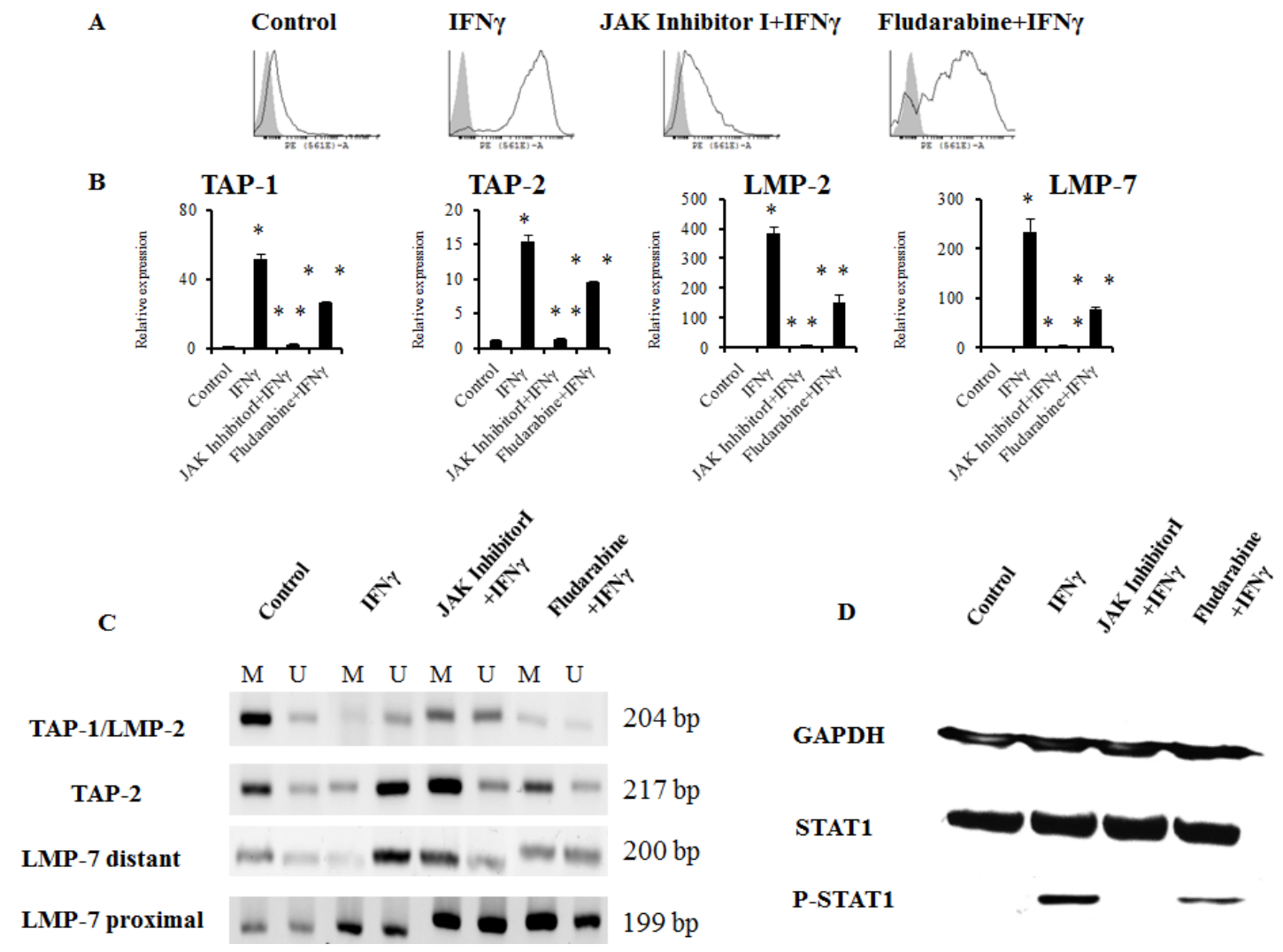

Figure 6: JAK/STAT inhibitors abrogated IFN $\gamma$-induced DNA demethylation of the APM gene promoters in TC-1/A9 cells. Inhibitor of Janus kinases (JAK inhibitor 1), as well as STAT1 phosphorylation inhibitor fludarabine, blocked the IFN $\gamma$ induction of the MHC class I cell-surface expression (A), as well as APM gene activation (B), and caused impaired demethylation of the corresponding gene promoter regions (C). Both inhibitors blocked IFN $\gamma$-induced STAT1 phosphorylation (D). The effect of fludarabine was much weaker, as compared to Janus kinase inhibitor $1 .{ }^{*}$ denotes significant changes $(\mathrm{P}<0.05$ determined in Student's t-test $)$ as compared to the values from untreated control cells. ** denotes significant changes $(\mathrm{P}<0.05$ determined in Student's t-test) as compared to the values from TC-1/ A9 cells after IFN $\gamma$ treatment. Biological triplicates were used for the analysis. In all experiments, error bars show standard deviations. Relative expression numbers represent the percentage of the $\beta$-actin expression levels. The levels of relative gene expression were presented as fold changes compared to the levels found in control samples. $U=$ unmethylated primer, $M=$ methylated primer. Experiments with JAK inhibitor 1 and fludarabine were repeated five and two times, respectively, with similar results. 
silencing was observed for LMP-2 LMP-7, TAP-1, TAP-2. Based on these results, we focused on the analysis of the four APM genes that were silenced. However, we cannot exclude that the changes in $\mathrm{H}-2, \beta 2$-microglobulin, tapasin or calnexin expression (and their upregulation upon the IFN $\gamma$ treatment) can also contribute to the modulation of MHC class I cell-surface expression.

Our data demonstrate that IFN $\gamma$-mediated activation of the APM genes and MHC class I expression in two tumour cell lines with reversible MHC class I expression defects was strongly associated with DNA demethylation of multiple APM genes located in the MHC locus. The promoter sequences of the studied APM genes in TC-1/A9 cells were also more methylated as compared to parental TC- 1 cells, suggesting that APM gene methylation is involved in MHC class I downregulation on tumour cells that escape from the specific immunity. The data were obtained using four experimental tumour cell lines distinct in origin (transformed by viral oncogenes or by a chemical mutagen) and in metastatic potential.

The finding that the IFN $\gamma$-mediated cell signalling can change the methylation status of the promoter regions of multiple genes contributes to our knowledge of the mechanisms underlying regulation of antigen processing and presentation in the context of MHC class I at the transcriptional level. So far, very little is known about the involvement of DNA demethylation in the regulation of multiple genes mediated by the IFN $\gamma$ signalling pathway. To our knowledge, there is only one study showing that IFN $\gamma$-mediated induction of the indole 2,3-dioxygenase (IDO)-1 expression was associated with DNA demethylation of the IDO-1 gene [24]. Setiadi et al. in 2007 observed that changes in histone acetylation and chromatin remodelling underlie induction of the TAP-1 expression by IFN $\gamma$ in TAPdeficient tumour cells [13] and, moreover, massive IFN $\gamma$-induced chromatin remodelling of the entire MHC locus, in which both TAP and $L M P$ genes are located, has been shown by Christova et al. [14]. The MHC genomic region became decondensed, and this was associated with STAT1 phosphorylation followed by binding of the chromatin remodelling enzyme BRG1 at specific sites and subsequent RNA-polymerase II recruitment and histone hyperacetylation, which appeared 2-4 $\mathrm{h}$ after the treatment. Our data add to the story and suggest that IFN $\gamma$ induced MHC locus chromatin remodelling and histone modifications are associated with DNA demethylation of multiple regions within this genomic locus, resulting in multiple gene expression and increased MHC class I molecule number on the cell surface. Interestingly, the $L M P-7$ gene expression was regulated in our experiments in the same manner as other tested APM genes, although the methylation status in the region close upstream to the initiation codon rather remained demethylated. However, demethylation was observed in the more distant region. It is therefore plausible that this gene is controlled by elements located in the wider region of the MHC locus. Important conclusions can be drawn from the kinetics of these phenomena. DNA demethylation can be either passive, which means dependent on DNA replication when the nascent DNA strains are not methylated due to the DNA methyltransferase deficiency, or active, fast and replication-independent [25]. The data from our kinetic study demonstrated that the DNA demethylation of the $T A P$ and $L M P$ gene promoter regions was relatively fast, as massive DNA demethylation was seen $6 \mathrm{~h}$ after the IFN $\gamma$ treatments, which roughly corresponded with the kinetics of histone acetylation reported elsewhere and discussed above [14], suggesting an interplay between histone acetylation and DNA demethylation. This is in agreement with the current view on the epigenetic transcription regulation and gene silencing in tumour cells [26]. For comparison, maximum levels of DNA demethylation in the cells treated with DNMTi inhibitor 5-AC were observed 24 after the treatment. This fast kinetics suggests that the demethylation process was active and not dependent on DNA replication, unlike 5AC-mediated demethylation, which requires drug incorporation into DNA and blocks methylation of nascent DNA chains due to methyltransferases inhibition [27]. Interestingly, cytokine-induced DNA demethylation was demonstrated in a study in which TGF $\beta$ signalling resulted in active DNA demethylation and $\mathrm{p} 15^{\text {ink4b }}$ tumour suppressor gene expression [28]. We also demonstrated strong association of the DNA demethylation with increased histone acetylation. It is of note that we demonstrate induction of acetylation at histone H3K18, since hypoacetylation at this position has been linked to poor prognosis in several cancers [29].

The data from this and our previous studies $[15,18]$ show that the expression of the studied APM genes in MHC class I-deficient tumours can be increased both by IFN $\gamma$ and DNA methyltransferase inhibitors. Thus, IFN $\gamma$ can in some instances serve as a DNA demethylating agent and, on the other hand, DNA methyltransferase inhibitors can upregulate part of the genes that are under the IFN $\gamma$ signalling pathway control. This means that DNA methyltransferase inhibitors can partially mimic the IFN $\gamma$ effects on selected immunomodulatory genes, which can be very important for explanation of the immunomodulatory antitumour effects of these compounds.

The data were complemented by a set of transcriptome analyses based on the comparison of cells treated either with a DNMTi DAC, in combination with a histone deacetylase inhibitor TSA or with IFN $\gamma$. Two cell lines were included into this experiment: TC-1/A9 is sensitive to both DAC/TSA and IFN $\gamma$ treatments, when RVP3 cell line is sensitive to DAC/TSA treatment but resistant to IFN $\gamma$. Comparative analysis of TC-1/A9 cells treated with either molecules showed a set of 32 genes commonly upregulated (gene set GS-COM) and a set of 73 
genes upregulated in IFN $\gamma$ treatment only (GS-IFN). Both gene sets present significant enrichment for "Cell Death Of Tumour Cell lines". Interestingly, genes implicated in this term in GS-COM gene set comprise IDO-1 which has already been demonstrated as demethylated by IFN $\gamma$ in previous studies [24].

GS-COM presents a clear and significant enrichment for antigen-presenting machinery and immunomodulatory genes. It is of importance that the upregulation of APM genes by the epigenetic agents was also seen in an IFN $\gamma$ non-responding cell line. This represents further evidence demonstrating epigenetic regulation of selected immunomodulatory genes controlled by IFN $\gamma$-mediated signalling. Consistent with this finding, the RVP3 cell line (resistant to IFN $\gamma$ ) treated with DAC/TSA, shows a similar list of APM pathway-enriched upregulated genes in common with those found upregulated in IFN $\gamma$-treated TC-1/A9 cells. This further confirms the implication of a downstream machinery implicating DNA demethylation for regulating the expression of antigen-presentation molecules triggered by, but not specific to, the IFN $\gamma$ transduction cascade.

Collectively, this study documents that IFN $\gamma$ can act as an epigenetic modifier and induce DNA demethylation of a number of genes, especially those involved in antigen processing and presentation.

\section{MATERIALS AND METHODS}

\section{Cell lines}

MHC class I-positive cell line TC-1 was obtained by in vitro co-transfection of murine lung C57BL/6 cells with HPV16 E6/E7 and activated human Ha-ras (G12V) oncogenes [30]. The TC-1/A9 (MHC class I-deficient) cell line [19] was obtained from TC-1 tumours developed in immunized mice. Both TC- 1 and TC-1/A9 cells were maintained in RPMI 1640 medium supplemented with 10\% FCS, 2 mM L-glutamine and antibiotics. E6/E7-expressing MHC class I-deficient cell line MK16/I/IIIABC (MK16), unlike TC-1 and TC-1/ A9 metastatic, derived from kidney $\mathrm{C} 57 \mathrm{BL} / 6$ cells [31] and murine fibrosarcoma cell line MC15 [32] obtained from methylcholanthrene-treated C57BL/10 mice were maintained under the same conditions as TC-1. The RVP3 cell line [33] was maintained in RPMI 1640 medium supplemented with 10\% FCS, 2 mM L-glutamine and antibiotics. The TRAMP-C2 tumour cell line (ATCC collection) was established from a prostate of a PB-Tag C57BL/6 (TRAMP) mouse [34]. The TRAMP-C2 cells were maintained in D-MEM medium supplemented with 5\% FCS, Nu-Serum IV (5\%; BD Biosciences, Bedford, MA, USA), $0.005 \mathrm{mg} / \mathrm{ml}$ bovine insulin (Sigma, St Louis, MO), dehydroisoandrosterone (DHEA, 10 nM; Sigma) and antibiotics. All cell lines were cultured at $37^{\circ} \mathrm{C}$ in a humidified atmosphere with $5 \% \mathrm{CO}_{2}$. Cells were cultured in fresh medium for $24 \mathrm{~h}$, after which the medium was removed and the cells were grown in medium containing either $\mathrm{rIFN} \gamma(50 \mathrm{U} / \mathrm{ml}, \mathrm{R} \& \mathrm{D}$ Systems, Minneapolis, USA ) or $5 \mu \mathrm{M}$ 5AC (Sigma). Except for the kinetic studies, cells were cultured for $48 \mathrm{~h}$ and harvested for analysis.

\section{Flow cytometry}

Cell suspensions were prepared from the cell cultures. Cell surface MHC class I expression on tumour cells was determined using $\mathrm{PE}$ anti- $\mathrm{H}-2 \mathrm{D}^{\mathrm{b}}$ (clone KH95) and PE anti- H-2K $\mathrm{K}^{\mathrm{b}}$ (AF6-88.5) antibodies. Flow cytometry was performed using an LSR II flow cytometer (BD Biosciences, San Jose, CA), and 10,000 cells were counted. Antibodies used, including the relevant isotypic control, were obtained from Pharmingen, San Diego, CA.

\section{Real-time quantitative RT-PCR}

Total RNA was extracted with RNeasy Mini Kit (Qiagen). The amount of $1 \mu \mathrm{g}$ of RNA was reverse transcribed to cDNA using random hexamer primers from GeneAmp RNA PCR Core Kit (Applied Biosystems, Foster City, CA) in a $20 \mu \mathrm{L}$ reaction volume at $42^{\circ} \mathrm{C}$ for 30 min. Quantification of PCR products was performed in 10 $\mu \mathrm{L}$ of Lightcycler 480 SYBR Green I Master mix (Roche) using a real-time PCR Lightcycler (Roche). DNA was denatured at $95^{\circ} \mathrm{C}$ for $2 \mathrm{~min}$; then followed 45 cycles of denaturation at $95^{\circ} \mathrm{C}$ for $25 \mathrm{~s}$, annealing at $60^{\circ} \mathrm{C}$ for $45 \mathrm{~s}$, elongation at $72^{\circ} \mathrm{C}$ for $1 \mathrm{~min}$ and incubation at $80^{\circ} \mathrm{C}$ for 5 s. cDNAs were amplified with specific primers for $\beta$-actin, $T A P-1, L M P-2, T A P-2$, and $L M P-7$. The list of the TAP1, TAP-2, LMP-2, LMP-7 and reference genes and their primer sequences have been described elsewhere $[15,18]$. Fold changes in the transcript levels were calculated using $\mathrm{C}_{\mathrm{T}}$ values standardized to $\beta$-actin, used as the endogenous reference gene control. All samples were run in biological triplicates. For statistical analysis of qPCR the Student's t-test was used. Differences between experimental and control samples with $\mathrm{P}<0.05$ were considered to be statistically significant. The levels of relative gene expression were presented as fold changes compared to the levels found in control samples.

\section{Bisulphite modification, methylation-specific PCR (MSP) and bisulphite sequencing}

Total DNA was extracted with DNeasy Blood \& Tissue Kit (Qiagen). Treatment of DNA from TC-1/A9, TC-1, TRAMP-C2 and RVP3 cells with sodium bisulphite and methylation-specific PCR (MSP) analysis of the $T A P-1$, TAP-2, LMP-2, LMP-7 promoter regions were 
performed with Bisulphite Epitect kit (Qiagen, Hilden, Germany) according to the manufacturer's protocol. In order to identify $\mathrm{CpG}$ islands within the promoter region of the antigen-processing genes, MSP analysis was performed with primers designed with the program METHPRIMER. The list of the TAP-1/LMP-2 and TAP-2 primer sequences has been described elsewhere $[15,18]$. Two CpG island containing regions within the LMP-7 upstream sequences were investigated, the primer sequences spanning the more distant to the transcription start have been published previously [15] and the sequences of the primers spanning $\mathrm{CpG}$ islands more proximal to the transcription start were as follows: $L M P-7$ MSP Un, 5' TAGGAGGGATATATGAAAAGGTTTG (forward) and AAAATATTAAACAAATCCACCTAAACATA (reverse); LMP-7 MSP Me, 5' TAGGAGGGATATATGAAAAGGTTC (forward) and TATTAAACAAATCCACCTAAACGTA (reverse). Within $T A P-2$, upstream sequences were investigated for $\mathrm{CpG}$ islands at positions -207 and -214 from the transcription start with forward primer and $\mathrm{CpG}$ islands at positions -26 and -40 from the transcription start with reverse primer. Within the TAP-1/LMP-2 upstream sequences a $\mathrm{CpG}$ island was investigated at position +119 from the transcription start with forward primer and $\mathrm{CpG}$ islands at positions +278 and +281 from the transcription start with reverse primer. With the $L M P-7$ distant primers, $\mathrm{CpG}$ islands were investigated at positions $-1219,-1233$ and -1238 from the transcription start with forward primer and a $\mathrm{CpG}$ island at position -1087 from the transcription start with reverse primer. With the $L M P-7$ proximal primers, a $\mathrm{CpG}$ island was investigated at position -335 from the transcription start with forward primer and $\mathrm{CpG}$ islands at positions -186 and -190 from the transcription start with reverse primer. The program for PCR was as follows: $95^{\circ} \mathrm{C}$ for $2 \mathrm{~min}$, then 35 cycles of $95^{\circ} \mathrm{C}$ for $2 \mathrm{~min}, 55^{\circ} \mathrm{C}$ for $2 \mathrm{~min}, 73^{\circ} \mathrm{C}$ for $1: 30 \mathrm{~min}$. At the end a final extension period of $73^{\circ} \mathrm{C}$ for 10 min was added. The PCR products were analysed with gel electrophoresis.

For bisulphite sequencing, another set of primers that amplified both methylated and unmethylated sequences were designed to directly determine the nucleotides resistant to bisulphite conversion. Their sequences were as follows: TAP2 BSP, 5, TTTTGGGTTTAGGTAAGTTTTTTT (forward) and TCTTCTCAAACTAAATCTCCTAAA (reverse); TAP-1/LMP-2 BSP, 5' AGTTTTAGGGGTTTTTGATTATTTTAT (forward) and AACTAATAAAACTAACTAAAAATACTA (reverse); LMP-7 BSP, 5' GTAGTTTTTGGGTAGATAATGTTT (forward) and AAAACCACAATACCAAAAAAAAA (reverse). Twenty-five $\mathrm{CpG}$ islands within the TAP2 upstream sequences were investigated, the primer sequences spanning the region from -264 to +76 from the transcription start. Thirty $\mathrm{CpG}$ islands within the TAP-1/ $L M P$-2 upstream sequences were investigated, the primer sequences spanning the region from -335 to +168 from the transcription start. Twenty-five $\mathrm{CpG}$ islands within the $L M P-7$ upstream sequences were investigated, the primer sequences spanning the region from -502 to +130 from the transcription start. The program for PCR was as follows: $95^{\circ} \mathrm{C}$ for $5 \mathrm{~min}$, then 25 cycles of $95^{\circ} \mathrm{C}$ for $50 \mathrm{~s}, 58^{\circ} \mathrm{C}$ for 2 $\min , 72^{\circ} \mathrm{C}$ for $1: 30 \mathrm{~min}$ and then 15 cycles of $95^{\circ} \mathrm{C}$ for 45 $\mathrm{s}, 54^{\circ} \mathrm{C}$ for $2 \mathrm{~min}, 72^{\circ} \mathrm{C}$ of $1: 30 \mathrm{~min}(+2 \mathrm{~s}$ every cycle). At the end, a final extension period of $72^{\circ} \mathrm{C}$ for $10 \mathrm{~min}$ was added. The PCR products were cloned using pGEM ${ }^{\circledR}-\mathrm{T}$ Easy Vector System I (Promega). Eleven clones for each of the different DNA sources were sequenced (Applied Biosystem, USA) after thermo-cycle sequencing reaction using the 3.1 version kit.

\section{JAK/STAT pathway inhibition}

JAK Inhibitor I (Cat. No. 420099, Calbiochem) was added into cell cultures $1 \mathrm{~h}$ before the IFN $\gamma$ treatment at a concentration of $2.5 \mu \mathrm{M}$. The primary target of JAK Inhibitor I is murine JAK1, its secondary targets are JAK2, JAK3 and TYK2. Fludarabine (Sigma) was used $24 \mathrm{~h}$ prior to the IFN $\gamma$ treatment at a final concentration of $50 \mu \mathrm{M}$. Cellular effects of fludarabine were specifically associated with the molecular switch-off of signal transducer and activator of transcription (STAT)-1 activation, without affecting other STAT proteins [35].

\section{Western blot analysis}

Whole-cell protein extracts were prepared from cell line TC-1/A9 using lysis buffer containing $20 \mathrm{mM}$ HEPES ( $\mathrm{pH}$ 7.9), $150 \mathrm{mM} \mathrm{NaCl}, 1 \mathrm{mM}$ ethylenediaminetetraacetic acid (EDTA), 1\% Triton X-100, 10\% glycerol, $1 \mathrm{mM}$ dithiotreitol, and protease or phosphatase inhibitor cocktail tablets (Complete/PhosSTOP, Roche). Proteins $(30 \mu \mathrm{g})$ were separated in 12\% SDS-PAGE gel and transferred to a nitrocellulose membrane (162-0115,Bio$\mathrm{Rad})$. The membrane was blocked in $0.1 \%$ Tris-buffered saline Tween (TBST), 5\% skimmed milk for $1 \mathrm{~h}$ at room temperature and incubated overnight at $4^{\circ} \mathrm{C}$ with rabbit polyclonal antibody against STAT1 (Cat. No. 9172S, Cell Signaling) and rabbit monoclonal antibody against the tyrosine-phosphorylated form of STAT1 (Cat. No. 9167S, Cell Signaling). The primary antibody was diluted 1:1000 in TBST containing 5\% BSA. After extensive washing, the blot was incubated for $1 \mathrm{~h}$ at room temperature with anti-rabbit horseradish peroxidase-conjugated secondary antibody (Cat. No. 7074, Cell Signaling) diluted 1:1000 in TBST containing 5\% BSA. After extensive washing of the blots, the bound antibodies were visualized using chemiluminescence (LumiGLO ${ }^{\circledR}$ Reagent, Cell Signaling). GAPDH levels were analysed using rabbit monoclonal antibody (2118S, Cell Signaling; dilution $1: 1000)$ and used as a control for equal loading. 


\section{Chromatin immunoprecipitation assay}

Chromatin immunoprecipitation (ChIP) assays were performed as described previously [36] with minor modifications. Briefly, for ChIP experiments, TC-1 or TC-1/A9 cells were grown in $150 \mathrm{~cm}^{2}$ culture flasks (TPP) and stimulated with IFN $\gamma(50 \mathrm{U} / \mathrm{mL})$ or left untreated. Two days later the cells were fixed directly in the flasks by addition of $1 / 10$ volume of CRS buffer $(11 \%(\mathrm{v} / \mathrm{v})$ formaldehyde, $100 \mathrm{mM} \mathrm{NaCl}, 1 \mathrm{mM}$ EDTA, $0.5 \mathrm{mM}$ EGTA, $50 \mathrm{mM}$ HEPES pH 8; Sigma) for 10 min at $4{ }^{\circ} \mathrm{C}$. Cross-linking was stopped by the addition of glycine (final concentration $0.125 \mathrm{M}$ ) at $4^{\circ} \mathrm{C}$ for 5 $\mathrm{min}$. Then, the cells were harvested and resuspended in RIPA buffer (50 mM Hepes, pH 8.0, $150 \mathrm{mM} \mathrm{NaCl}, 1.0 \%$ Triton X-100, 0.1\% sodium deoxycholate, $0.1 \%$ SDS, 1 mM EDTA, 0.5 mM EGTA; Sigma) containing protease inhibitor cocktail-Complete (Roche), sonicated (Branson 450 ) and subjected to ChIP analysis. Cell lysate was precleared with $0.05 \mathrm{mg} / \mathrm{ml}$ yeast tRNA (Sigma)/protein A/G-agarose beads (Santa Cruz) and then incubated with the rabbit antibody for acetylated histone H3 (Lys18) (Cell Signaling, dilution 1/25). After several washes, DNA bound to the immunocomplexes was obtained and decross-linked by overnight incubation at $65^{\circ} \mathrm{C}$. DNA was recovered via phenol/chloroform extraction. The amount of precipitated DNA was analysed using the LightCycler 480 Real-Time PCR System (Roche). Purified (by phenol extraction) input chromatin (chromatin that was not subjected to ChIP) was analysed in control PCR reactions. For the promoter analysis, we designed the following PCR primers which span the TAP-1/LMP-2 bidirectional promoter: forward GGCAAATCTGCCCAGAGA and reverse CCTAGCCTGGGACTC TCGAC; TAP-2 promoter: forward CACGGCAGTGAAGTGAAAGC and reverse CAAAAGAACTCACCTGCGGC; LMP7 promoter: forward GGACCTAAAGACCCCTGTGC and reverse AGCGGAGGACTGAATAGGGT. The negative control experiments were performed with primers amplifying the gene desert region of DNA: forward CCATGCACATGCTAGCGCTCGA and reverse TCCGAAAGCTGGGAGAAGGGGT.

\section{Transcriptome analysis}

Cell culture protocol published by Suzuki et al. in 2002 [37] was applied with minor modifications. Briefly, for comparative transcriptome analysis, TC-1/A9 and RVP-3 cells were treated either with IFN $\gamma(100 \mathrm{U} / \mathrm{ml})$ for $24 \mathrm{~h}$ or with a combination of $3 \mu \mathrm{M} 5-2^{\prime}$-deoxyazacytidine (DAC) for the $48 \mathrm{~h}$ (medium was replaced with fresh one with inhibitor after $24 \mathrm{~h}$ ) and $30 \mathrm{ng} / \mathrm{ml}$ Trichostatin A (TSA) for the additional $24 \mathrm{~h}$. RNA was extracted from biological triplicates with RNeasy Mini Kit (Qiagen). The amount of $1 \mu \mathrm{g}$ of RNA was subjected to the transcriptomic analysis, using Illumina Mouse WG6 bead chips in the Genomic Core Facility at the Institute of Molecular Genetics in Prague. Raw data extraction was performed using Illumina BeadStudio version 2. Raw data analyses were performed using R 3.0.0 software with the packages lumi and limma for data normalization (quantile), transformation $(\log 2)$ and probe filtering (probes with detection p-values $>0.01$ in all samples removed). At least three independently prepared samples ("biological triplicates") per group were analysed. Statistical analyses were performed using eBayes algorithm with BenjaminiHochberg p-value correction. Functional annotations were performed using the IPA module from Ingenuity ${ }^{\circledR}$ software. The transcriptome analysis data were deposited at the GEO public functional genomics data repository under the reference Series No. GSE53469.

\section{ACKNOWLEDGEMENTS}

This work was supported by grant No. 301/10/2174 from the Grant Agency of the Czech Republic, by RVO 68378050 , and in part by the Clinigene Network of Excellence for the Advancement of Gene Transfer and Therapy, EU-FP6 Project No. 018933, the European Union FP6 project CompuVac (LSHB-CT-04-005246), by French state funds within the Investissements d'Avenir program (ANR-11-IDEX-0004-02; LabEx Transimmunom) and by IGA NT14461 from the Grant Agency of the Ministry of Health of the Czech Republic. The authors are grateful to Renata Turečková for excellent technical help and to Šárka Takáčová for editorial help. V. V. and I. S. are Ph.D. students supported in part by the Faculty of Science, Charles University, Prague.

\section{REFERENCES}

1. Jones PA, Baylin SB. The epigenomics of cancer. Cell. 2007; 128: 683-692.

2. Esteller M. Epigenetics in cancer. N Engl J Med. 2008; 358 : 1148-1159.

3. Sigalotti L, Coral S, Fratta E, Lamaj E, Danielli R, Di Giacomo AM, Altomonte M, Maio M. Epigenetic modulation of solid tumors as a novel approach for cancer immunotherapy. Semin Oncol. 2005; 32: 473-478.

4. Tomasi TB, Magner WJ, Khan AN. Epigenetic regulation of immune escape genes in cancer. Cancer Immunol Immunother. 2006; 55: 1159-1184.

5. Garrido F, Ruiz-Cabello F, Cabrera T, Perez-Villar JJ, Lopez-Botet M, Duggan-Keen M, Stern PL. Implications for immunosurveillance of altered HLA class I phenotypes in human tumours. Immunol Today. 1997; 18: 89-95.

6. Bubeník J. Tumour MHC class I downregulation and immunotherapy (Review). Oncol Rep. 2003; 10: 20052008.

7. Reiniš M. Immunotherapy of MHC class I-deficient tumors. 
Future Oncol. 2010; 6: 1577-1589.

8. Seliger B. Novel insights into the molecular mechanisms of HLA class I abnormalities. Cancer Immunol Immunother. 2012; 61: 249-254.

9. Garrido F, Cabrera T, Aptsiauri N. "Hard" and "soft" lesions underlying the HLA class I alterations in cancer cells: implications for immunotherapy (Review). Int J Cancer. 2010; 127: 249-256.

10. Seliger B, Wollscheid U, Momburg F, Blankenstein T, Huber C. Coordinate downregulation of multiple MHC class I antigen processing genes in chemical-induced murine tumor cell lines of distinct origin. Tissue Antigens. 2000; 56: 327-336.

11. Garcia-Lora A, Martinez M, Algarra I, Gaforio JJ, Garrido F. MHC class I-deficient metastatic tumor variants immunoselected by $\mathrm{T}$ lymphocytes originate from the coordinated downregulation of APM components. Int J Cancer. 2003; 106: 521-527.

12. Gabathuler R, Reid G, Kolaitis G, Driscoll J, Jefferies WA. Comparison of cell lines deficient in antigen presentation reveals a functional role for TAP-1 alone in antigen processing. J Exp Med. 1994; 180: 1415-1425.

13. Setiadi AF, David MD, Seipp RP, Hartikainen JA, Gopaul $R$, Jefferies WA. Epigenetic control of the immune escape mechanisms in malignant carcinomas. Mol Cell Biol. 2007; 27: 7886-7894.

14. Christova R, Jones $\mathrm{T}$, Wu PJ, Bolzer A, Costa-Pereira AP, Watling D, Kerr IM, Sheer D. P-STAT1 mediates higher-order chromatin remodelling of the human $\mathrm{MHC}$ in response to IFNgamma. J Cell Sci. 2007; 120: 3262-3270.

15. Manning J, Indrova M, Lubyova B, Pribylova H, Bieblova J, Hejnar J, Simova J, Jandlova T, Bubenik J, Reinis M. Induction of MHC class I molecule cell surface expression and epigenetic activation of antigen-processing machinery components in a murine model for human papilloma virus 16-associated tumours. Immunology. 2008; 123: 218-227.

16. Setiadi AF, Omilusik K, David MD, Seipp RP, Hartikainen J, Gopaul R, Choi KB, Jefferies WA. Epigenetic enhancement of antigen processing and presentation promotes immune recognition of tumors. Cancer Res. 2008; 68: 9601-9607.

17. Khan AN, Gregorie CJ, Tomasi TB. Histone deacetylase inhibitors induce TAP, LMP, Tapasin genes and MHC class I antigen presentation by melanoma cells. Cancer Immunol Immunother. 2008; 57: 647-654.

18. Simova J, Pollakova V, Indrova M, Mikyskova R, Bieblova J, Stepanek I, Bubenik J, Reinis M. Immunotherapy augments the effect of 5-azacytidine on HPV16-associated tumours with different MHC class I-expression status. British Journal of Cancer. 2011; 105: 1533-1541.

19. Smahel M, Síma P, Ludvíková V, Marinov I, Pokorná D, Vonka V. Immunisation with modified HPV16 E7 genes against mouse oncogenic TC-1 cell sublines with downregulated expression of MHC class I molecules.
Vaccine. 2003; 21: 1125-1136.

20. Martini M, Testi MG, Pasetto M, Picchio MC, Innamorati G, Mazzocco M, Ugel S, Cingarlini S, Bronte V, Zanovello P, Krampera M, Mosna F, Cestari T, Riviera AP, Brutti N, Barbieri O, Matera L, Tridente G, Colombatti M, Sartoris S. IFN-gamma-mediated upmodulation of MHC class I expression activates tumor-specific immune response in a mouse model of prostate cancer. Vaccine. 2010; 28: 35483557.

21. Darnell JE Jr, Kerr IM, Stark GR. Jak-STAT pathways and transcriptional activation in response to IFNs and other extracellular signaling proteins. Science. 1994; 264: 14151421.

22. Dunn GP, Koebel CM, Schreiber RD. Interferons, immunity and cancer immunoediting. Nat Rev Immuno. 2006; 6: 836848.

23. Serrano A, Castro-Vega I, Redondo M. Role of gene methylation in antitumor immune response: implication for tumor progression. Cancers (Basel). 2011; 3: 1672-1690.

24. Xue ZT, Sjögren HO, Salford LG, Widegren B. An epigenetic mechanism for high, synergistic expression of indoleamine 2,3-dioxygenase 1 (IDO1) by combined treatment with zebularine and IFN- $\gamma$ : Potential therapeutic use in autoimmune diseases. Molecular Immunology. 2012; 51: 101-111.

25. Niehrs C. Active DNA demethylation and DNA repair. Differentiation. 2009; 77: 1-11.

26. Vaissière T, Sawan C, Herceg Z. Epigenetic interplay between histone modifications and DNA methylation in gene silencing. Mutat Res. 2008; 659: 40-48.

27. Creusot F, Acs G, Christman JK. Inhibition of DNA methyltransferase and induction of Friend erythroleukemia cell differentiation by 5-azacytidine and 5-aza-2'deoxycytidine. J Biol Chem. 1982; 257: 2041-2048.

28. Thillainadesan G, Chitilian JM, Isovic M, Ablack JN, Mymryk JS, Tini M, Torchia J. TGF- $\beta$-dependent active demethylation and expression of the p15ink4b tumor suppressor are impaired by the ZNF217/CoREST complex. Mol Cell. 2012; 46: 636-649.

29. Seligson DB, Horvath S, McBrian MA, Mah V, Yu H, Tze S, Wang Q, Chia D, Goodglick L, Kurdistani SK. Global levels of histone modifications predict prognosis in different cancers. Am J Pathol. 2009; 174: 1619-1628.

30. Lin KY, Guarnieri FG, Staveley-O'Carroll KF, Levitsky HI, August JT, Pardoll DM, Wu TC. Treatment of established tumors with a novel vaccine that enhances major histocompatibility class II presentation of tumor antigen. Cancer Res. 1996; 56: 21-26.

31. Smahel M, Sobotkova E, Bubenik J, Simova J, Zak R, Ludvikova V, Hajkova R, Kovarik J, Jelinek F, Povysil C, Marinov J, Vonka V. Metastatic MHC class I-negative mouse cells derived by transformation with human papillomavirus type 16. Br J Cancer. 2001; 84: 374-380.

32. Bubeník J, Indrová M, Nemecková S, Malkovský M, Von 
Broen B, Pálek V, Anderlíková J. Solubilized tumourassociated antigens of methyl-cholanthrene-induced mouse sarcomas. Comparative studies by in vitro sensitization of lymph-node cells, macrophage electrophoretic mobility assay and transplantation tests. Int J Cancer. 1978; 21: 348355 .

33. Bubeník J, Koldovský P, Svoboda J, Klement V, Dvorák R. Induction of tumours in mice with three variants of rous sarcoma virus and studies on the immunobiology of these tumours. Folia Biol (Praha). 1967; 13: 29-39.

34. Foster BA, Gingrich JR, Kwon ED, Madias C, Greenberg NM. Characterization of prostatic epithelial cell lines derived from transgenic adenocarcinoma of the mouse prostate (TRAMP) model. Cancer Res. 1997; 57: 33253330 .

35. Torella D, Curcio A, Gasparri C, Galuppo V, De Serio D, Surace FC, Cavaliere AL, Leone A, Coppola C, Ellison GM, Indolfi C. Fludarabine prevents smooth muscle proliferation in vitro and neointimal hyperplasia in vivo through specific inhibiton of STAT-1 activation. Am J Physiol Heart Circ Physiol. 2007; 292: H2935-2943.

36. Lukas J, Mazna P, Valenta T, Doubravska L, Pospichalova V, Vojtechova M, Fafilek B, Ivanek R, Plachy J, Novak J, Korinek V. Dazap2 modulates transcription driven by the Wnt effector TCF-4. Nucleic Acids Res. 2009; 37: 3007 3020 .

37. Suzuki H, Gabrielson E, Chen W, Anbazhagan R, van Engeland M, Weijenberg MP, Herman JG, Baylin SB. A genomic screen for genes upregulated by demethylation and histone deacetylase inhibition in human colorectal cancer. Nat Genet. 2002: 31: 141-149. 